\title{
Comparison of antibacterial effect of seven 1-monoglycerides on food-borne pathogens or spoilage bacteria
}

\author{
Leona Buňková ${ }^{1}$, František Buňka ${ }^{2}$, Rahula Janiš ${ }^{1}$, Jiří Krejčí ${ }^{1}$, Iva Doležálková1, \\ Zdeněk Pospíšil ${ }^{3}$, Jan Rủžička ${ }^{4}$, Bohuslava Tremlová ${ }^{5}$ \\ ${ }^{1}$ Department of Fat, Tenside and Cosmetics Technology, Faculty of Technology, \\ Tomas Bata University in Zlin, Czech Republic \\ ${ }^{2}$ Department of Food Technology and Microbiology, Faculty of Technology, \\ Tomas Bata University in Zlin, Czech Republic \\ ${ }^{3}$ Department of Mathematics and Statistics, Faculty of Science, Masaryk University, Brno, Czech Republic \\ ${ }^{4}$ Department of Environment Protection Engineering, Faculty of Technology, \\ Tomas Bata University in Zlin, Czech Republic \\ ${ }^{5}$ Department of Vegetable Foodstuffs and Plant Production, Faculty of Veterinary Hygiene and Ecology, \\ University of Veterinary and Pharmaceutical Sciences Brno, Czech Republic
}

Received February 21, 2010

Accepted June 15, 2010

\begin{abstract}
The aim of this study was to compare under the same conditions in vitro the inhibitory effects of seven 1-monoglycerides (MAG) containing fatty acids with a medium chain on ten strains of food-borne pathogens or spoilage gram-positive and gram-negative bacteria (Bacillus cereus, Bacillus subtilis, Enterococcus faecalis, Micrococcus luteus, Staphylococcus aureus, Citrobacter freundii, Escherichia coli, Proteus mirabilis, Salmonella enterica ser. Enteritidis and Pseudomonas aeruginosa) and on their growth indicatos. The inhibitory effect of MAGs (monocaprylin, monocaprin, monolaurin, monomyristin, monopalmitin, MAG of undecanoic and 10-undecenoic acids) at a concentration of $25-1500 \mathrm{mg} \cdot \mathrm{l}^{-1}$ was observed. Growth of bacteria in the presence of MAG was studied by means of optical density of bacteria for $24 \mathrm{~h}$. The data were modelled through a Gompertz equation and the lag-time, the maximum specific growth rate and the maximal value reached were calculated. MAGs inhibited mainly the growth of gram-positive bacteria, which was shown by the extended lag-time, decrease in specific growth rate and decrease in cell density. Inhibitory effects of tested MAGs could be ranked from point of view of the minimum inhibitory concentration: MAG-C12:0 > MAG-C11:0 > MAG-C10:0 > MAG-C14:0 > MAG-C11:1 $>$ MAG-C8:0 > MAG-C16:0. In vitro, no significant inhibitory effects of 1-monoglycerides, with the exception of the highest concentrations applied, on the growth of gram-negative bacteria were detected. The main contribution of this study is to compare the effects of several MAG containing fatty acids with a medium chain under the same conditions on the growth indicators of bacteria.
\end{abstract}

Inhibition effect, esters of glycerol, microorganism, Gompertz model, specific growth rate, lag-time

In the environment of foodstuffs, many food-borne pathogens, animal pathogens or spoilage microorganisms that can be transmitted to humans may be proliferated. Undesirable growth of microorganisms on the surface and inside animal products may be health hazardous. Therefore, preservation of food and its ingredients has become an important issue nowadays. In the food processing industry, antimicrobial substances belong to the most important groups of additives (Davidson and Branen 2005; Kačániová et al. 2009). Antimicrobial substances should be an integral part of foodstuffs and could even improve their functional properties. These substances include monoglycerides (MAG) (Kabara and Marshall 2005) that are used for their emulsifying abilities in the food processing industry (Moonen and Bas 2004). Moreover, they can improve rheological properties of many foodstuffs, e.g. dairy or bakery products (Ravi et al. 2000; Buňka et al. 2007).

Antimicrobial activity of fatty acids and monoglycerides as their other functional properties depends on the number of carbon atoms and on the presence of double bonds

Address for correspondence:

Bohuslava Tremlová

Department of Vegetable Foodstuffs and Plant Production

Faculty of Veterinary Hygiene and Ecology

University of Veterinary and Pharmaceutical Sciences Brno

Palackého 1-3, 61242 Brno, Czech Republic

Phone: +420541562700

Fax: +420 549243020

E-mail: tremlovab@vfu.cz

http://www.vfu.cz/acta-vet/actavet.htm 
in the fatty acid chain (Thormar and Hilmarsson 2007). Under certain conditions, fatty acids and monoglycerides can inhibit the growth of vegetative forms of pathogenic bacteria, viruses (Thormar and Hilmarss on 2007), spore-forming bacteria (Mansour et al. 1999; Skrivanova et al. 2006) or yeasts (Bergs s on et al. 2001). However, food composition can influence the inhibitory effect of both monoglycerides and fatty acids. Certain substances of foodstuffs (e.g. starch, serum albumin, phospholipids, cholesterol) can react with these molecules and thus decrease their inhibitory effects against undesirable microorganisms. Moreover, in some foodstuffs the use of some 1-monoglycerides could be unsuitable because negative changes of their organoleptic properties might occur (Davidson and Branen 2005; Buňka et al. 2007).

Fatty acids and monoglycerides are lipophilic substances and therefore the target site of their attack is the cytoplasmic membrane of cells. Although the mechanism for the antibacterial activity of fatty acids and their derivatives has not been fully recognized, it was found that they cause damage to the cell membrane used as a permeable barrier and inhibit the transport of amino acids to the cell (Dufour et al. 2007; Thormar and Hilmarss on 2007). Another hypothesis is based on the penetration of fatty acids with a short and medium chain in a non-dissociated form into bacterial cells and their dissociation inside the cells, which leads to acidification of the cell contents (Sado $\mathrm{Kamdem}$ et al. 2008). Reduction in the intracellular $\mathrm{pH}$ can lead to inactivation of the intracellular enzymes ( $\mathrm{Nair}$ et al. 2005). The inhibitory effect of monoglycerides can be increased by organic acids (Tokarskyy and Marshall 2008) or chelation agents (Branen and Davidson 2004).

There are many studies dealing with the antimicrobial effect of the individual MAG. However, studies which would compare the effects of several MAG containing fatty acids under the same conditions with a medium chain on the growth indicators of bacteria have not been published yet. Therefore, the aim of this study was to compare the inhibitory effects of seven 1-monoglycerides on selected gram-positive and gram-negative bacteria which represent pathogenic microorganisms and/or microorganisms that participate in food spoilage. For these purposes, a set of 1-monoglycerides containing medium-chain fatty acids (monocaprylin, monocaprin, monolaurin, monomyristin, monopalmitin) and less common fatty acids with an odd number of carbons (monoglycerides of undecanoic and undecenoic acid) was chosen. These monoglycerides can be used as additives in the food processing industry.

\section{Materials and Methods}

The inhibitory effects of selected 1-monoglycerides were tested in the following gram-positive bacteria: Bacillus cereus CCM 2010, Bacillus subtilis subsp. spizizenii CCM 4062, Enterococcus faecalis CCM 4224, Micrococcus luteus CCM 732, Staphylococcus aureus subsp. aureus CCM 3953 and gram-negative bacteria: Citrobacter freundii CCM 7187, Escherichia coli CCM 3954, Proteus mirabilis CCM 7188, Pseudomonas aeruginosa CCM 3955, Salmonella enterica subsp. enterica ser. Enteritidis CCM 4420. All bacteria used were obtained from the Czech Collection of Microorganisms (CCM).

Suspension of bacteria was prepared by inoculating $10 \mathrm{ml}$ of Nutrient Broth No 2 (Oxoid, Basingstoke, UK) by $25 \mu \mathrm{l}$ of the corresponding one-day inoculum of bacteria. The bacteria were subsequently grown at a temperature of $30 \pm 1{ }^{\circ} \mathrm{C}$ for $24 \mathrm{~h}$.

Solutions and chemicals

Monoglycerides were produced by adding an appropriate fatty acid to glycidol under the catalytic influence of chromic ions according to the method of Janiš et al. (2000). The chemicals used were obtained from SigmaAldrich (St. Louis, USA). The following 1-monoglycerides were produced: monocaprylin (MAG-C8:0), monocaprin (MAG-C10:0), monoundecanoylglycerol (MAG-C11:0), mono-10-undecenoylglycerol (MAG-C11:1), monolaurin (MAG-C12:0), monomyristin (MAG-C14:0) and monopalmitin (MAG-C16:0). The products were purified using triple re-crystallization from ethanol. Purity of all the MAGs used was better than $99 \%$ as determined by HPLC. Content of residual catalyst given as $\mathrm{Cr}$ (III) was less than $20 \mathrm{mg} \cdot \mathrm{kg}^{-1} \mathrm{as} \mathrm{determined}$ by atomic absorption spectroscopy.

Stock solutions of the 1 -monoglycerides tested $(100 \mathrm{ml})$ were prepared at a concentration of $25 \mathrm{~g} \cdot \mathrm{l}^{-1}(\mathrm{w} / \mathrm{v})$ in absolute ethanol (LachNer, Neratovice, Czech Republic). Thereafter, the stock solutions were sterilized 
by filtration (Millipore with the porosity of $0.22 \mu \mathrm{m}$ ) and stored in closed test tubes at a temperature of $4{ }^{\circ} \mathrm{C}$

Observation of the effect of 1-monoglycerides on the cell growth

After putting $250 \mu \mathrm{l}$ of the cultivation medium (Mueller-Hinton Broth, HiMedia, Bombai, India) with or without monoglycerides into wells, $5 \mu \mathrm{l}$ of 24-h bacterial suspension hundredfold diluted, at the 1.9-8.6 $\times 10^{4}$ $\mathrm{CFU} \cdot \mathrm{ml}^{-1}$ density of bacteria were added to each well. In all cases, the growth of cells was observed at the following concentrations of MAGs: 25, 50, 100, 250, 500, 1000 and $1500 \mathrm{mg} \cdot \mathrm{l}^{-1}(\mathrm{w} / \mathrm{v})$. Before autoclaving, the $\mathrm{pH}$-value of the cultivation medium (with or without monoglycerides) were adjusted to $6.70-6.80 \mathrm{using} 1 \mathrm{~mol} \cdot 1^{-1}$ $\mathrm{NaOH}$ or $\mathrm{HCl}$. Wells filled with $250 \mu \mathrm{l}$ of the cultivation medium without the corresponding monoglyceride and $5 \mu \mathrm{l}$ of the suspension of bacteria were used as a positive control. Non-inoculated wells containing $255 \mu \mathrm{l}$ of broth with MAG at an appropriate concentration were used as negative control. At all concentrations of MAGs including the controls, the growth was observed in at least 5 wells of the microtiter plates. Similarly the inhibition effect of ethanol as the dissolvent for MAGs at the concentration of up to $7 \%(\mathrm{v} / \mathrm{v})$ was tested.

The bacterial growth at $25 \pm 1{ }^{\circ} \mathrm{C}$ (the chosen temperature could correspond to the room temperature) was observed spectrophotometricaly by means of TECAN Sunrise TW/TC machine (TECAN, Austria). The growth of bacteria was observed for $24 \mathrm{~h}$ by using the values of optical density (OD-values) of the cell suspension. The growth of bacteria was measured at a wavelength of $600 \mathrm{~nm}$ at 30-min intervals. Before each measurement, the sample was shaken for $10 \mathrm{~s}$. Each experiment was done in triplicate.

In order to exclude the inhibitory effect of ethanol (which served as dissolvent for MAGs), an experiment was conducted before this study. An appropriate amount of absolute ethanol (without MAG) was added to the cultivation medium. As the results showed, ethanol at the concentrations tested $(<7 \% \mathrm{v} / \mathrm{v})$ had no effect on the growth of the selected bacteria.

Data analysis

The effect of a given 1-monoglyceride at a certain concentration on the microorganisms tested was evaluated according to following growth indicators: the lag-time $(\lambda)$, the $A$-value and the maximum specific growth rate $\left(\mu_{m}\right)$. Indicator $A$ (the maximal value reached) for a given MAG at a certain concentration was compared in a relative expression to the $A$-value of the positive control ( $A$-value of the growth without the presence of MAG).

Based on the results, the logarithm of the relative OD-value in time $t\left[y=\ln \left(\mathrm{OD}_{t} / \mathrm{OD}_{0}\right)\right]$ was calculated. The dependence of the logarithm of the relative OD-value $(y)$ on the time of cultivation $(t)$ was described by means of the three-parameter Gompertz model:

$$
y=A \cdot \exp \left\{-\exp \left[\frac{\mu_{m} \cdot e}{A}(\lambda-t)+1\right]\right\}
$$

where: $\mu_{m}$ is the maximum specific growth rate $\left(\mathrm{h}^{-1}\right) ; \lambda$ is the lag-time; $A$ is the asymptote $\left[A=\ln \left(\mathrm{OD}_{\infty} / \mathrm{OD}_{0}\right)\right]$ defined as the maximal value reached (Zwietering et al. 1990). The estimates of $\mu_{m}, \lambda$ and $A$ parameters were determined by nonlinear regression analysis (nonlinear least squares regression) for the following conditions $\mu_{m}>0, \lambda>0$ and $A>0$. The Marquardt-Levenburg method was applied by means of Unistat ${ }^{\mathbb{B}} 5.5$ software (Unistat Ltd., London, UK). Standard deviations were added to the estimated parameters. Quality of the models designed was evaluated by means of correlation coefficient $(r)$. Correlation coefficients $(r)$ of modelled dependence of the logarithm relative OD-value $(y)$ on the time of cultivation $(t)$ were at an interval of $\langle 0.89 ; 0.99\rangle$.

For the overall comparison of efficiency of the 1-monoglycerides tested in the individual concentrations, a threeway analysis of variance (ANOVA) in Unistat ${ }^{\circledR} 5.5$ software was used.

\section{Results}

\section{Gram-positive bacteria}

In the presence of MAG-C8:0 at higher concentrations tested (1000 and $1500 \mathrm{mg} \cdot \mathrm{l}^{-1}$ ), no growth (measured by an increase in OD) of gram-positive bacteria was detected after 24-h cultivation. In the most gram-positive bacteria tested, total inhibition of their growth was not detected even at the highest concentration of MAG-C16:0. Figs 1, 2 and Table 1 show that with the increasing concentration of both MAG-C8:0 and MAG-C16:0, the relative $A$-value and specific growth rate in the gram-positive bacteria tested decrease gradually, and at the same time lag-time extension occurs.

Monocaprin affected the gram-positive bacteria tested at lower concentrations than MAG-C8:0 and MAG-C16:0. The concentrations of MAG-C10:0 causing inhibition of growth of the gram-positive bacteria were used within the range of $50-500 \mathrm{mg} \cdot \mathrm{l}^{-1}$ (Table 1, Figs 1 and 2).

MAG-C12:0 showed the best inhibitory effects on the gram-positive strains tested. In 


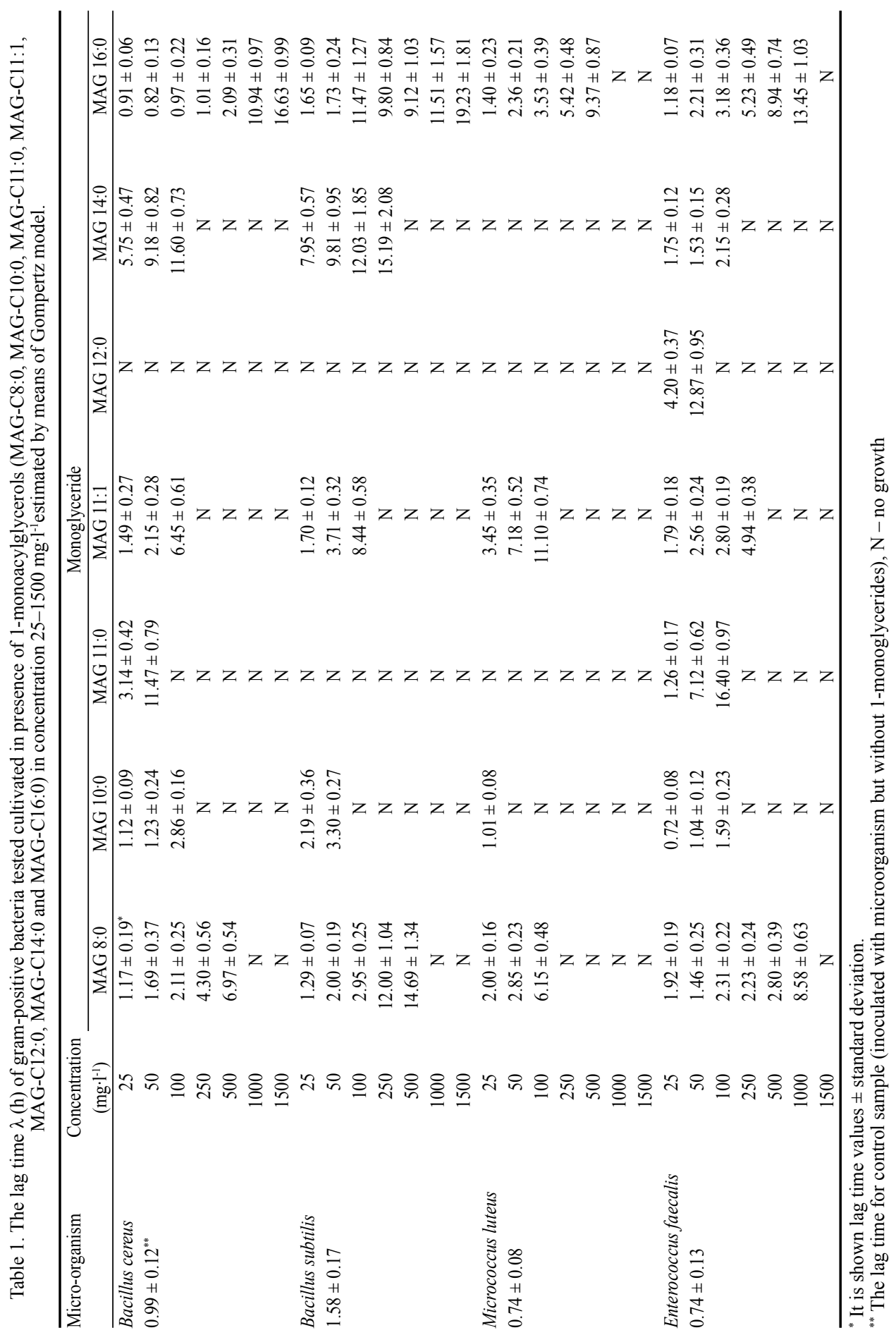




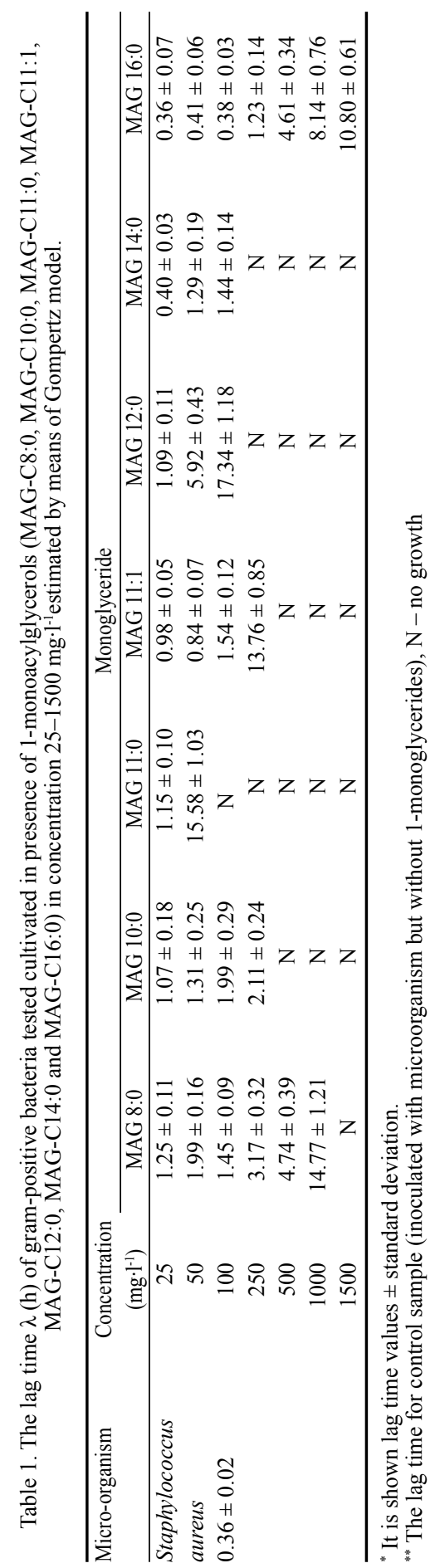

B. cereus CCM 2010, B. subtilis CCM 4062 and $M$. luteus CCM 732, total growth inhibition was detected after the application of the lowest concentration of MAG-C12:0 tested $\left(25 \mathrm{mg} \cdot \mathrm{l}^{-1}\right)$. In Ent. faecalis CCM 4224 and Staph. aureus CCM 3953, growth inhibition occurred after the application of MAG-C12:0 at $100 \mathrm{mg} \cdot \mathrm{l}^{-1}$ and $250 \mathrm{mg} \cdot \mathrm{l}^{-1}$ respectively.

The inhibitory effect on the growth of bacteria in M. luteus CCM 732 was observed after the application of MAG-C14:0 at the lowest concentration tested. During the cultivation in the presence of MAG-C14:0 at concentrations of 25 $-100 \mathrm{mg} \cdot \mathrm{l}^{-1}$, bacteria of the genus Bacillus showed a significant lag-time extension against the control and a decrease in the specific growth rate (Figs 1, 2; Table 1).

The inhibition effect of the gram-positive bacteria growth occurred after the addition of MAG-C11:0 at concentrations of 25-250 mg.l ${ }^{-1}$. The gram-positive bacteria had to adapt to the presence of MAG-C11:0 for a longer time as is clear from the lag-time period (Table 1). It is clear from Figs 1 and 2 that after the application of lower concentrations of MAG-C11:0, a decrease in the relative $A$-value in comparison with the control as well as a decrease in the specific growth rate occurred. In MAG-C11:1, the inhibition of bacterial growth occurred after the application of MAG at higher concentrations. This MAG appeared to be the third least effective one (after MAG-C16:0 and MAG-C8:0).

\section{Gram-negative bacteria}

Within the 1-monoglycerides tested, MAG-C10:0 at a concentration of $1500 \mathrm{mg} \cdot \mathrm{l}^{-1}$ had the strongest inhibitory effect on the growth of the gram-negative bacteria tested. In this 1-monoglyceride, the growth of the gram-negative bacteria with the exception of Pr. mirabilis CCM 7188 was not detected. Within the range of lower concentrations tested $(<1500$ $\mathrm{mg} \cdot \mathrm{l}^{-1}$ ), a decrease in the relative $A$-value (Fig. 3 ) and in the specific growth rate and lag-time extension (data not shown) of the gram-negative bacteria tested were observed.

Significant reduction in the growth of $E$. coli CCM 3954, Salm. Enteritidis CCM 4420 and Cit. freundii CCM 7187 also occurred after the addition of MAG-C8:0 to the cultivation medium at concentrations of $\geq 500 \mathrm{mg} \cdot 1^{-1}$ (Fig. 3).

In the presence of 1-monoglycerides such as MAG-C11:0, MAG-C11:1, MAG-C12:0, 


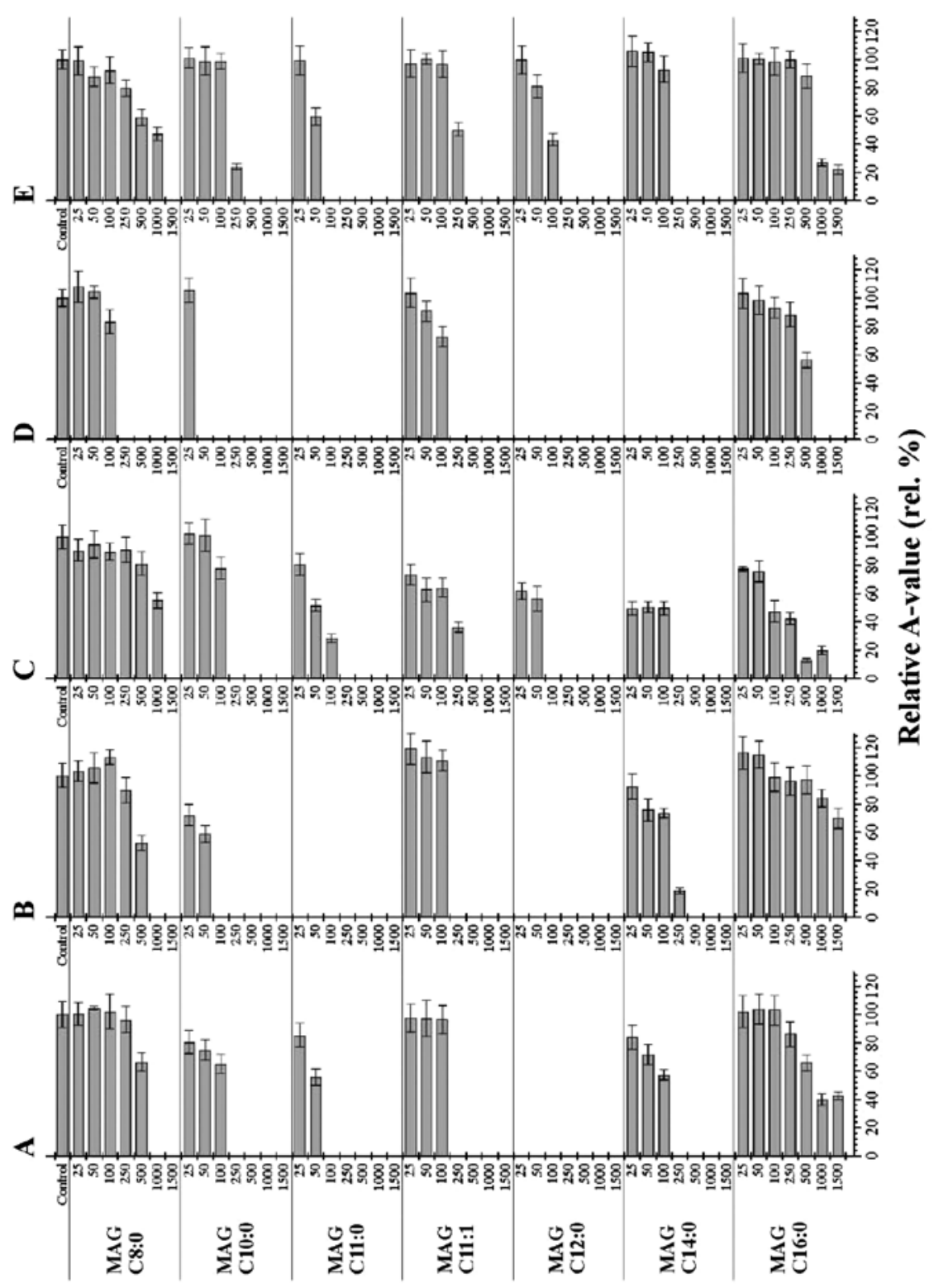

Type of 1-monoglyceride and its concentration $\left(\mathrm{mg} \cdot \mathrm{l}^{-1}\right)$

Fig. 1. A-values (the maximal values reached estimated by means of Gompertz model) of 5 tested gram-positive bacteria cultivated in presence of 1-monoglycerides (MAG-C8:0, MAG-C10:0, MAG-C11:0, MAG-C11:1, MAG-C12:0, MAG-C14:0 and MAG-C16:0) at concentration 25-1500 mg:-1'.

A - Bacillus cereus CCM 2010; B - Bacillus subtilis CCM 4062; C - Enterococcus faecalis CCM 4224; D Micrococcus luteus CCM 732; E-Staphylococcus aureus CCM 3953. A-values are expressed relatively to control sample (inoculated with microorganism but without 1-monoglycerides). Error bars display standard deviation. 


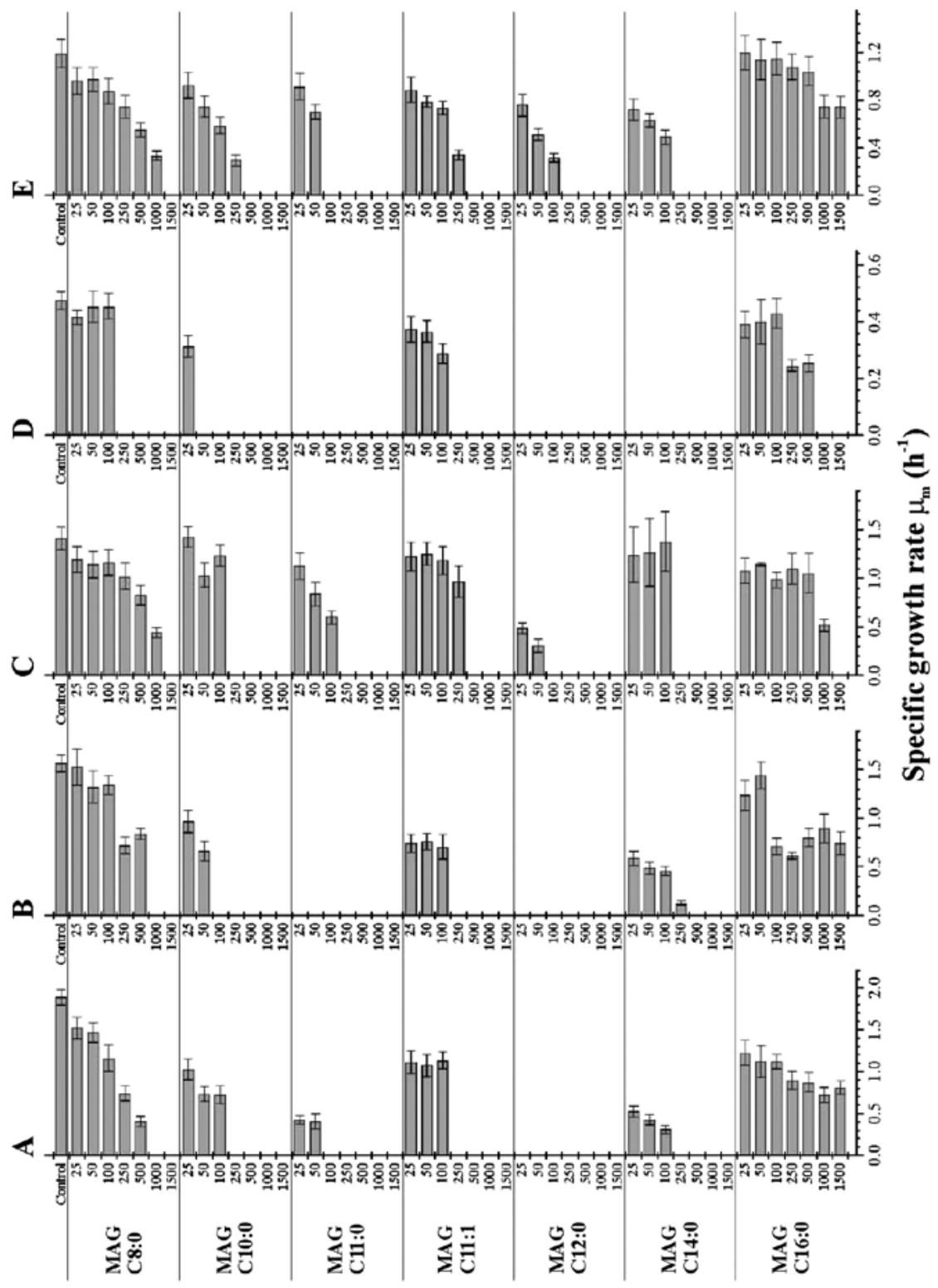

Type of 1-monoglyceride and its concentration $\left(\mathrm{mg}^{-\mathrm{l}^{-1}}\right)$

Fig. 2. Specific growth rates $\mu_{\mathrm{m}}\left(\mathrm{h}^{-1}\right)$ (estimated by means of Gompertz model) of 5 tested gram-positive bacteria cultivated in presence of 1-monoglycerides (MAG-C8:0, MAG-C10:0, MAG-C11:0, MAG-C11:1, MAG-C12:0, MAG-C14:0 and MAG-C16:0) at concentration 25-1500 mg: $\mathrm{l}^{-1}$.

A - Bacillus cereus CCM 2010; B - Bacillus subtilis CCM 4062; C - Enterococcus faecalis CCM 4224; D - Micrococcus luteus CCM 732; E - Staphylococcus aureus CCM 3953. Error bars display standard deviation. 


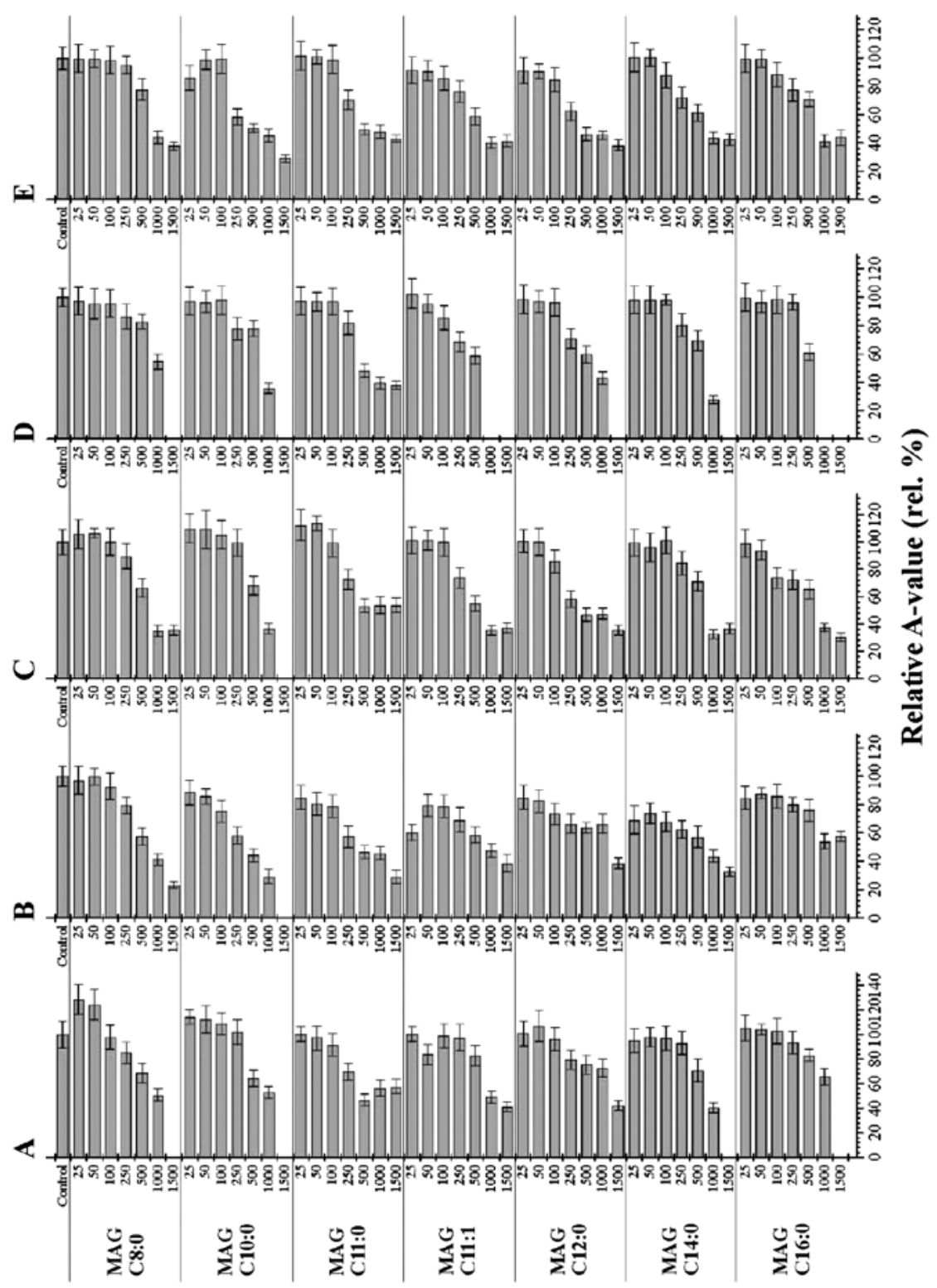

Type of 1-monoglyceride and its concentration $\left(\mathrm{mg}^{-1} \mathrm{l}^{-1}\right)$

Fig. 3. A-values (the maximal values reached estimated by means of Gompertz model) of 5 tested gram-negative bacteria cultivated in presence of 1-monoglycerides (MAG-C8:0, MAG-C10:0, MAG-C11:0, MAG-C11:1, MAG-C12:0, MAG-C14:0 and MAG-C16:0) at concentration 25-1500 $\mathrm{mg} \cdot \mathrm{l}^{-1}$.

A - Citrobacter freundii CCM 7187; B - Escherichia coli CCM 3954; C - Salmonella Enteritidis CCM 4420; D - Pseudomonas aeruginosa CCM 3955; E - Proteus mirabilis CCM 7188. A-values are expressed relatively to control sample (inoculated with microorganism but without 1-monoglycerides). Error bars display standard deviation. 
MAG-C14:0 and MAG-C16:0, a significant decrease in growth characteristics of gramnegative bacteria was usually detected only at concentrations of $\geq 1000 \mathrm{mg} \cdot \mathrm{l}^{-1}$ (Fig. 3).

Antimicrobial effects on gram-positive and gram-negative strains tested

After the application of MAG, the group of gram-positive bacteria used had a significantly lower specific growth rate $\mu_{m}(P<0.001)$ and the maximal $A$-value reached $(P<0.001)$ compared to the group of gram-negative bacteria tested. The difference in lag-time $\lambda$ between the two groups of gram-positive and gram-negative bacteria was not proved $(P \geq 0.05)$. In addition, the three-way analysis of variance showed that within both groups of the bacteria: the effect of the individual MAG differed $(P<0.05)$; with the increasing concentration of MAG, the maximal $A$-value was decreasing significantly $(P<0.001)$ and the lag-time $\lambda$ was extending $(P<0.001)$; the increasing concentration of MAG caused a decrease in the maximum specific growth rate $\mu_{m}(P<0.05)$.

\section{Discussion}

Monoglyceride of caprylic acid had only weak antimicrobial effect on bacteria tested. Nair et al. (2005) observed the effect of MAG-C8:0 on the streptococci and staphylococci causing mastitis in beef cattle and discovered that this MAG at the concentrations ranging from 5460 to $10915 \mathrm{mg} \cdot \mathrm{l}^{-1}$ leads to a significant reduction in the number of cells. Also, MAG-C8:0 at higher concentration $\left(10915 \mathrm{mg} \cdot \mathrm{l}^{-1}\right)$ has an inhibitory effect on Listeria monocytogenes contaminating meat products (Garcia et al. 2007).

Růžička et al. (2003) discovered lower inhibitory concentrations of MAG-C10:0 on staphylococci $\left(150 \mathrm{mg} \cdot \mathrm{l}^{-1}\right)$ compared to our study. On the other hand, the minimum inhibitory concentrations of MAG-C10:0 in Ent. faecalis and B. subtilis were the same as those in our study.

In this study Ps. aeruginosa CCM 3955 appeared to be the most sensitive gram-negative bacterium of all tested MAGs. This finding is quite interesting because many bacteria of the genus Pseudomonas are generally considered to be resistant to unfavourable environmental conditions. Růžička et al. (2003) did not discover any antimicrobial effects of $1000 \mathrm{mg} \cdot \mathrm{l}^{-1}$ of MAG-C10:0 and $500 \mathrm{mg} \cdot \mathrm{l}^{-1}$ of MAG-C12:0 on Ps. aeruginosa. Similarly, Branen and Davidson (2004) did not detect any inhibition of cell growth in Ps. fluorescens under the influence of MAG-C12:0 at a concentration of $250 \mathrm{mg} \cdot \mathrm{l}^{-1}$. Higher concentrations of the MAG used are not presented in any of the works cited. However, our results show that total inhibition of the growth of Ps. aeruginosa can be achieved by means of higher concentrations of both MAG-C10:0 and MAG-C12:0. Within $24 \mathrm{~h}$, lower concentrations of both mentioned MAGs lead only to a slowdown in growth.

Our results are in accordance with other authors who have not found a more significant inhibitory effect of monoglycerides on enterobacteria. Růžička et al. (2003) did not detect an inhibitory effect of MAG-C12:0 on E. coli or Klebsiella pneumoniae. No inhibitory effect of the same MAG against Salmonella, Escherichia and Klebsiella was observed (McLay et al. 2002; Marounek et al. 2003; Preuss et al. 2005; Skrivanova et al. 2006). It was possible to enhance the antimicrobial effect of 1-monoglycerides on enterobacteria by other factors, e.g. a decrease in $\mathrm{pH}$ of the environment (Sado Kamdem et al. 2008) or by the addition of other inhibitory agents to the cultivation medium, e.g. eugenol (Blaszyk and Holley 1998), ethylenediaminetetraacetic acid (Branen and Davidson 2004) or lactoperoxidase system (McLay et al. 2002).

The MAG-C12:0 was efficient on gram-positive bacteria tested. The inhibitory concentrations of MAG-C12:0 of B. cereus or B. anthracis are within the range of 25-70 mg. $\mathrm{l}^{-1}$ (Lee et al. 2002; Preuss et al. 2005). Our results also correspond to these values. Higher concentrations $\left(250 \mathrm{mg} \cdot \mathrm{l}^{-1}\right)$ had to be applied in order to inhibit bacteria Bacillus spp. in milk. In this case, MAG-C12:0 can inhibit not only the growth of Bacillus 
spp. but also the production and germination of spores (Mansour et al. 1999; Mansour and Millière 2001). In our case, the most resistant gram-positive bacterium to the effect of MAG-C12:0 was Staph. aureus CCM 3953, the inhibition of which was caused by this MAG at a concentration of $250 \mathrm{mg} \cdot \mathrm{l}^{-1}$. This minimum inhibitory concentration is higher than the one detected in other strains of staphylococci (Lee et al. 2002; Růžička et al. 2003; Preuss et al. 2005).

Within the 1-monoglycerides tested, MAG-C10:0, MAG-C11:0 and MAG-C12:0 show the best inhibitory effects on the growth of gram-positive bacteria. MAG-C8:0 and MAG-C16:0 seem to be the least effective against the gram-positive bacteria tested.

When comparing the inhibitory effects of monoglycerides containing medium-chain fatty acids with both even and odd number of carbons on the microorganisms tested, there is no significant difference in their inhibitory effect on bacterial growth. Thus, the opinion about better antibacterial effects of non-physiological monoglycerides containing fatty acids with an odd number of carbons has not been confirmed.

Gram-negative bacteria are relatively resistant to the effect of 1-monoglycerides (Thormar and Hilmarsson 2007), which is in accordance with our results. According to Bergsson et al. $(1999,2002)$ the inhibitory effect of monoglycerides was observed only in gram-negative bacteria which have clearly defined living conditions and which show a relatively low resistance to unfavourable environmental conditions. Among such kinds of bacteria, the following might be included e.g. Chlamydia trachomatis or Neisseria gonorrhoeae.

Gram-positive bacteria were more sensitive to the 1-monoglycerides tested than gramnegative bacteria. However, the exact mechanism for the effect of monoglycerides on bacteria which would explain this difference has not been fully discovered. Electron microscopy studies observed morphological changes of bacteria growing in the presence of MAGs showing damage of the cell membrane under the influence of MAG (Bergss on et al. 1998, 1999). Dufour et al. (2007) discovered that in mutant strains of Ent. faecalis, the resistance to monolaurin is caused by the changes in the cell surface and thus MAG cannot penetrate the cell and reach the place where it could act. It can be assumed that in grampositive bacteria, monoglycerides attack the cell (cytoplasm) membrane which loses its semi-permeability, which leads to damage of the bacterial cells. In gram-negative bacteria, it might be the outer membrane that is the place under attack, while there is no damage to the semi-permeability of the cell membrane and thus the bacteria are able to tolerate MAG. Different composition of the cell wall in gram-positive and gram-negative bacteria might be the cause of different effect of MAG on these two groups of bacteria.

In conclusion, the gram-positive food-borne and animal pathogens and/or food-borne spoilage bacteria tested were sensitive mainly to 1 -monoglycerides containing fatty acids with 10-14 carbons in the chain. Inhibitory effects of the MAG tested on gram-positive bacteria can be ranked in order of minimum inhibitory concentrations and growth indicators as follows: MAG-C12:0 > MAG-C11:0 > MAG-C10:0 > MAG-C14:0 > MAG-C11:1 > MAG-C8:0 > MAG-C16:0. The 1-monoglycerides used did not have any effect on the food-borne pathogens and/or food-borne spoilage gram-negative bacteria tested with the exception of the highest concentrations applied $\left(1500 \mathrm{mg} \cdot \mathrm{l}^{-1}\right)$.

\section{Acknowledgements}

This study was supported by projects of the Ministry of Education, Youth and Sports of the Czech Republic, MSM7088352101 and MSM6215712402.

\section{References}

Bergsson G, Arnfinnsson J, Karlsson SM, Steingrímsson Ó, Thormar H 1998: In vitro inactivation of Chlamydia trachomatis by fatty acids and monoglycerides. Antimicrob Agents Chemother 42: 2290-2294 
Bergsson G, Arnfinnsson J, Steingrímsson Ó, Thormar H 2001: In vitro killing of Candida albicans by fatty acids and monoglycerides. Antimicrob Agents Chemother 45: 3209-3212

Bergsson G, Steingrímsson Ó, Thormar H 1999: In vitro susceptibilities of Neisseria gonorrhoeae to fatty acids and monoglycerides. Antimicrob Agents Chemother 43: 2790-2792

Bergsson G, Steingrímsson Ó, Thormar H 2002: Bactericidal effects of fatty acids and monoglycerides on Helicobacter pylori. Int J Antimicrob Agents 20: 258-262

Blaszyk M, Holley RA 1998: Interaction of monolaurin, eugenol and sodium citrate on growth of common meat spoilage and pathogenic organisms. Int J Food Microbiol 39: 175-183

Branen J, Davidson PM 2004: Enhancement of nisin, lysozyme, and monolaurin antimicrobial activities by ethylenediaminetetraacetic acid and lactoferrin. Int J Food Microbiol 90: 63-74

Buňka F, Pavlínek V, Hrabě J, Rop O, Janiš R, Krejčí J 2007: Effect of 1-monoglycerides on viscoelastic properties of processed cheeses. Int J Food Propert 10: 819-828

Davidson PM, Branen AL 2005: Food antimicrobials - an introduction. In: Davidson PM, Sofos JN, Branen AL (Eds.): Antimicrobials in Food. CRC Press, Boca Raton, pp. 1-10

Dufour M, Manson JM, Bremer PJ, Dufour J-P, Cook GM, Simmonds RS 2007: Characterization of monolaurin resistance in Enterococcus faecalis. Appl Environ Microbiol 73: 5507-5515

Garcia M, Amalaradjou MAR, Nair MKM, Annamalai T, Surendranath S, Lee S, Hoagland T, Dzurec D, Faustman C, Venkitanarayanan K 2007: Inactivation of Listeria monocytogenes on frankfurters by monocaprylin alone or in combination with acetic acid. J Food Prot 70: 1594-1599

Janiš R, Krejčí J, Klásek A 2000: Preparation of 1-monoacylglycerols from glycidol and fatty acids catalyzed by the chromium(III)-fatty acid system. Eur J Lipid Sci Technol 102: 351-354

Kabara JJ, Marshall DL 2005: Medium-chain fatty acids and esters. In: Davidson PM, Sofos JN, Branen AL (Eds.): Antimicrobials in Food. CRC Press, Boca Raton, pp. 327-360

Kačániová M, Pavličová S, Haščík P, Kociubinski G, Kňazovická V, Sudzina M, Sudzinová J, Fikselová M 2009: Microbial communities in bees, pollen and honey from Slovakia. Acta Microbiol Immunol Hung 56: $285-295$.

Lee J-Y, Kim Y-S, Shin D-H 2002: Antimicrobial synergistic effect of linolenic acid and monoglyceride against Bacillus cereus and Staphylococcus aureus. J Agric Food Chem 50: 2193-2199

Mansour M, Amri D, Bouttefroy A, Linder M, Milliere JB 1999: Inhibition of Bacillus licheniformis spore growth in milk by nisin, monolaurin, and $\mathrm{pH}$ combinations. J Appl Microbiol 86: 311-324

Mansour M, Millière J-B 2001: An inhibitory synergistic effect of a nisin-monolaurin combination on Bacillus sp. vegetative cells in milk. Food Microbiol 18: $87-94$

Marounek M, Skřivanová E, Rada V 2003: Susceptibility of Escherichia coli to $\mathrm{C}_{2}-\mathrm{C}_{18}$ fatty acids. Folia Microbiol 48: 731-735

McLay JC, Kennedy MJ, O’Rourke A-L, Elliot RM, Simmonds RS 2002: Inhibition of bacterial foodborne pathogens by the lactoperoxidase system in combination with monolaurin. Int. J Food Microbiol 73: 1-9

Moonen H, Bas H 2004: Mono- and diglycerides. In: Whitehurst RJ (Ed.): Emulsifiers in Food Technology. Blackwell Publishing, Oxford, pp. 40-57

Nair MKM, Joy J, Vasudevan P, Hinckley L, Hoagland TA, Venkitanarayanan KS 2005: Antibacterial effect of caprylic acid and monocaprylin on major bacterial mastitis pathogens. J Dairy Sci 88: 3488-3495

Preuss HG, Echard B, Enig M, Brook I, Elliott B 2005: Minimum inhibitory concentrations of herbal essential oils and monolaurin for gram-positive and gram-negative bacteria. Mol Cel Biochem 272: 29-34

Ravi R, Manohar RS, Rao PH 2000: Influence of additives on the rheological characteristic and baking quality of wheat flours. Eur Food Res Technol 210: $202-208$

Růžička J, Velclová K, Janiš R, Krejčí J 2003: Antimicrobial effects of 1-monoacylglycerols prepared by catalytic reaction of glycidol with fatty acids. Eur Food Res Technol 217: 329-331

Sado Kamdem S, Guerzoni ME, Baranyi J, Pin C 2008: Effect of capric, lauric, and $\alpha$-linolenic acids on the division time distributions of single cells of Staphylococcus aureus. Int J Food Microbiol 28: 122-128

Skrivanova E, Marounek M, Benda V, Brezina P 2006: Susceptibility of Escherichia coli, Salmonella sp. and Clostridium perfringens to organic acids and monolaurin. Vet Med 51: 81-88

Thormar H, Hilmarsson H 2007: The role of microbicidal lipids in host defense against

Tokarskyy O, Marshall DL 2008: Mechanism of synergistic inhibition of Listeria monocytogenes growth by lactic acid, monolaurin, and nisin. Appl Environ Microbiol 74: 7126-7129

Zwietering MH, Jongenburger I, Rombouts FM, Van't Riet K 1990: Modeling of the bacterial growth curve. Appl Environ Microbiol 56: 1875-1881 